\title{
WASH Benefits Bangladesh trial: management structure for achieving high coverage in an efficacy trial
}

Leanne Unicomb ${ }^{1 *}$, Farzana Begum ${ }^{1}$, Elli Leontsini², Mahbubur Rahman', Sania Ashraf², Abu Mohd Naser ${ }^{3}$, Fosiul A. Nizame ${ }^{1}$, Kaniz Jannat ${ }^{1}$, Faruqe Hussain ${ }^{1}$, Sarker Masud Parvez ${ }^{1}$, Shaila Arman', Moshammot Mobashara', Stephen P. Luby ${ }^{4}$ and Peter J. Winch ${ }^{2}$

\begin{abstract}
Background: Water, sanitation, and hygiene (WASH) efficacy trials deliver interventions to the target population under optimal conditions to estimate their effects on outcomes of interest, to inform subsequent selection for inclusion in routine programs. A systematic and intensive approach to intervention delivery is required to achieve the high-level uptake necessary to measure efficacy. We describe the intervention delivery system adopted in the WASH Benefits Bangladesh study, as part of a three-paper series on WASH Benefits Intervention Delivery and Performance.
\end{abstract}

Methods: Community Health Workers (CHWs) delivered individual and combined WASH and nutrition interventions to 4169 enrolled households in geographically matched clusters. Households were provided with free enabling technologies and supplies, integrated with parallel behaviour-change promotion. Behavioural objectives were drinking treated, safely stored water, safe feces disposal, handwashing with soap at key times, and age-appropriate nutrition behaviours (birth to 24 months). The intervention delivery system built on lessons learned from prior WASH intervention effectiveness, implementation, and formative research studies. We recruited local CHWs, residents of the study villages, through transparent merit-based selection methods, and consultation with community leaders. CHW supervisors received training on direct intervention delivery, then trained their assigned CHWs. CHWs in turn used the technologies in their own homes. Each CHW counseled six to eight intervention households spread across a 0.2-2.2$\mathrm{km}$ radius, with a 1:12 supervisor-to-CHW ratio. CHWs met monthly with supervisor-trainers to exchange experiences and adapt technology and behaviour-change approaches to evolving conditions. Intervention uptake was tracked through fidelity measures, with a priori benchmarks necessary for an efficacy study.

Results: Sufficient levels of uptake were attained by the fourth intervention assessment month and sustained throughout the intervention period. Periodic internal $\mathrm{CHW}$ monitoring resulted in discontinuation of a small number of low performers.

Conclusions: The intensive intervention delivery system required for an efficacy trial differs in many respects from the system for a routine program. To implement a routine program at scale requires further research on how to optimize the supervisor-to-CHW-to-intervention household ratios, as well as other program costs without compromising program effectiveness.

(Continued on next page)

\footnotetext{
* Correspondence: leanne@icddrb.org

${ }^{1}$ Infectious Disease Division, Environmental Intervention Unit, Enteric and

Respiratory Disease Program, International Centre for Diarrhoeal Disease

Research, Bangladesh (icddr,b), 68 Shahed Tajuddin Ahmed Sarani,

Mohakhali, Dhaka 1212, Bangladesh

Full list of author information is available at the end of the article
}

(c) The Author(s). 2018 Open Access This article is distributed under the terms of the Creative Commons Attribution 4.0 International License (http://creativecommons.org/licenses/by/4.0/), which permits unrestricted use, distribution, and reproduction in any medium, provided you give appropriate credit to the original author(s) and the source, provide a link to the Creative Commons license, and indicate if changes were made. The Creative Commons Public Domain Dedication waiver (http://creativecommons.org/publicdomain/zero/1.0/) applies to the data made available in this article, unless otherwise stated. 
(Continued from previous page)

Trial registration: ClinicalTrials.gov, ID: NCC01590095. Registered on 2 May 2012.

Keywords: WASH Benefits trial, Intervention delivery, Behaviour change, Water, Sanitation, Handwashing, Child nutrition, Bangladesh

\section{Background}

Water, sanitation, and hygiene (WASH) interventions may include home water treatment, latrine construction, and handwashing promotion, typically promoted by community health workers (CHWs). Due to demonstrated effects of WASH interventions on child health outcomes, such as the effect of handwashing on diarrhoea [1], they have received considerable funding over the years from governments in and donor organizations for low- and middle-income countries [2-5]. However, a considerable research agenda remains regarding (1) the selection of specific WASH technologies and behaviours for inclusion in large-scale, routine programs and (2) how to achieve levels of use and maintenance of technologies that affect sustained adoption of behaviours under routine programmatic conditions sufficient to produce health impact.

Intervention efficacy, effectiveness research and implementation research studies that involve $\mathrm{CHWs}$, particularly to impart behaviour change, differ. There are different uptake goals, CHW-to-population ratios and systems for $\mathrm{CHW}$ management and supervision dependent on the size and scope of the study (Table 1). WASH efficacy studies typically examine the effects of specific WASH technologies and behaviors on outcomes of interest in order to inform their subsequent inclusion in routine programs (Table 1). To conduct efficacy studies, CHWs deliver different combinations of WASH interventions to the target population under optimal or ideal conditions (Table 1). In efficacy studies CHWs take great efforts to ensure that the behaviour-enabling technology is present and functional at the household level, and that they are being used (Table 2). This may include free distribution of the technology, and frequent visits by the CHWs to ensure adoption of the behaviours and address difficulties encountered with either the technologies or the behaviours. In contrast, to examine how to achieve high uptake of WASH interventions under near real-world and real-world conditions, researchers build on outcomes from efficacy research and conduct effectiveness research and implementation research (Tables 1 and 2).

This article describes the intervention delivery system adopted in the WASH Benefits study in rural Bangladesh, a large-scale efficacy trial of different combinations of WASH and child nutrition behaviour-change interventions delivered by CHWs [6]. The efficacy trial found that nutrition only and nutrition plus WASH interventions improved linear growth and decreased diarrhoea among recipient children [7]. The WASH Benefits interventions were selected from 2 years of pilot studies and the delivery methods aimed at sustained uptake are described in this paper, part of a three-paper series on WASH Benefits Intervention Delivery and Performance [8, 9]; the paper by Rahman et al. [8] describes fidelity measurement methods and monitoring;

Table 1 Comparison of uptake goals and implementation procedures for three categories of research on behaviour change interventions delivered by community health workers (CHWs)

\begin{tabular}{|c|c|c|c|c|c|}
\hline Type of research & $V^{2}$ alidity and causal inferences ${ }^{1}$ & $\begin{array}{l}\text { Level of control over } \\
\text { experimental conditions }{ }^{1}\end{array}$ & $\begin{array}{l}\text { Goals for level } \\
\text { of uptake }\end{array}$ & $\begin{array}{l}\text { CHW to } \\
\text { household ratio }\end{array}$ & $\begin{array}{l}\text { System for CHW management } \\
\text { and supervision }\end{array}$ \\
\hline Efficacy research & $\begin{array}{l}\text { Focus on internal validity: } \\
\text { can we draw causal } \\
\text { inferences between } \\
\text { interventions received } \\
\text { and outcomes observed? }\end{array}$ & $\begin{array}{l}\text { Highly controlled, } \\
\text { farther from } \\
\text { real-world conditions }\end{array}$ & $\begin{array}{l}\text { Technology } \\
\text { uptake: optimal } \\
\text { Behavioural uptake: } \\
\text { optimal }\end{array}$ & $\begin{array}{l}\text { Less than 1/ } \\
\text { 100, not a } \\
\text { real-world ratio }\end{array}$ & $\begin{array}{l}\text { Continuous oversight, } \\
\text { typically } 2-3 \text { times per } \\
\text { month. CHWs replaced } \\
\text { within } 1 \text { month of attrition } \\
\text { or critically low performance }\end{array}$ \\
\hline $\begin{array}{l}\text { Effectiveness } \\
\text { research }\end{array}$ & $\begin{array}{l}\text { Focus on external validity: } \\
\text { can the results be generalized } \\
\text { to programmatic settings } \\
\text { with near-real world conditions? }\end{array}$ & $\begin{array}{l}\text { Less controlled, near } \\
\text { real-world conditions }\end{array}$ & $\begin{array}{l}\text { Technology } \\
\text { uptake: near optimal } \\
\text { Behavioural uptake: } \\
\text { routine }\end{array}$ & $\begin{array}{l}\text { Ratio based } \\
\text { on national } \\
\text { Ministry of Health } \\
(\mathrm{MOH}) \text { policy. } \\
\text { Ongoing technical } \\
\text { support from } \\
\text { NGO } \text { staff }^{3}\end{array}$ & $\begin{array}{l}\text { Periodic oversight, typical } \\
\text { monthly or less. Facilitation } \\
\text { of problem resolution by } \\
\text { non-governmental } \\
\text { organization (NGO) }\end{array}$ \\
\hline $\begin{array}{l}\text { Implementation } \\
\text { research }\end{array}$ & $\begin{array}{l}\text { Focus on external validity: } \\
\text { can the results be generalized } \\
\text { to programmatic settings } \\
\text { with real-world conditions? }\end{array}$ & $\begin{array}{l}\text { Not controlled, } \\
\text { real-world conditions }\end{array}$ & $\begin{array}{l}\text { Technology } \\
\text { uptake: routine } \\
\text { Behavioural uptake: } \\
\text { routine }\end{array}$ & $\begin{array}{l}\text { Ratio based on } \\
\text { national } \mathrm{MOH} \\
\text { policy. } \\
\text { Limited technical } \\
\text { support from } \\
\text { NGO } \text { staff }^{4}\end{array}$ & $\begin{array}{l}\text { Oversight depends on } \\
\text { research question } \\
\text { Limited external } \\
\text { facilitation of problem } \\
\text { resolution }\end{array}$ \\
\hline
\end{tabular}

${ }^{1}$ Adapted from Curran et al. [10]; ${ }^{2}$ Described in more detail in Table $2 ;{ }^{3}$ Typically includes recruitment, training, provision of materials and job aids and on-going supervision; ${ }^{4}$ Typically includes training and provision of behaviour-change communication (BCC) materials and job aids 
Table 2 Content of behaviour-change interventions delivered by community health workers (CHWs) to achieve different levels of uptake

\begin{tabular}{|c|c|c|}
\hline \multirow[t]{2}{*}{ Desired uptake level } & \multicolumn{2}{|c|}{ Actions taken by CHWs during intervention delivery to achieve desired uptake level } \\
\hline & $\begin{array}{l}\text { Technology uptake: actions to ensure } \\
\text { access to technology }\end{array}$ & $\begin{array}{l}\text { Behaviour uptake: actions to promote } \\
\text { behaviour change and technology use }\end{array}$ \\
\hline Optimal / ideal & $\begin{array}{l}\text { - Technology distributed by CHWs/ project } \\
\text { - CHWs provide users with information on use and } \\
\text { maintenance of the technology } \\
\text { - CHWs conduct frequent home visits to verify that } \\
\text { technology is functional and in good working } \\
\text { order at all times, and intervene if technology } \\
\text { ceases to function }\end{array}$ & $\begin{array}{l}\text { - Behavioural recommendations explained by CHWs during } \\
\text { one or more initial home visits } \\
\text { - CHWs conduct frequent home visits to verify that people follow } \\
\text { behavioural recommendations, and intervene/problem solve if they } \\
\text { do not follow the recommendations }\end{array}$ \\
\hline Routine & $\begin{array}{l}\text { - Technology distributed by CHWs/ project } \\
\text { - CHWs provide users with information on use and } \\
\text { maintenance of the technology } \\
\text { - CHWs do not intervene directly to ensure functionality }\end{array}$ & $\begin{array}{l}\text { - Behavioural recommendations explained by CHWs during } \\
\text { one or more initial home visits } \\
\text { - CHWs do not intervene directly to ensure that people follow } \\
\text { the behavioural recommendations }\end{array}$ \\
\hline
\end{tabular}

the paper by Parvez et al. [9] describes methods and findings for intervention uptake. In this paper we describe both the intervention delivery system necessary to achieve the high level of uptake, and the difficulties encountered during intervention delivery and how they were addressed.

\section{Methods}

\section{Terminology and definitions}

We adapt terminology described previously [10], as follows:

- Dissemination: "An effort to communicate tailored information to target audiences with the goal of engagement and information use; dissemination is an inherent part of implementation"

- Intervention: "Health promotion activities being tested or implemented to improve health outcomes." (adapted from "Clinical Intervention")

- Intervention delivery (used in place of "Implementation" for the purpose of this manuscript) "An effort specifically designed to get best practice findings and related products into habitual and sustained use through appropriate change/uptake/adoption interventions"

For intervention uptake we draw a distinction between actions taken by CHWs to achieve behavioural versus technology uptake and further divide these between optimal and routine uptake to illustrate the differences in CHW-delivered interventions (Table 2).

\section{WASH Benefits intervention design}

The WASH Benefits Bangladesh cluster randomized controlled trial was conducted in four central Bangladesh districts; Tangail, Gazipur, Kishorgonj, and Mymensingh (Fig. 1). Details of the study design are described elsewhere [6]. In summary, the interventions included free provision of enabling technologies as follows: an insulated drinking-water storage container [11] (Lion Star Plastics, Sri Lanka) for treated stored water; a sani-scoop (a locally developed tool made specifically for the trial, based on previous research
[12] was used to remove feces from the household environment; a child's potty [13] (RFL, Bangladesh) to minimize child open defecation in the household environment; double-pit pour-flush improved latrines [14] for hygienic feces containment; handwashing stations and soapy water storage bottles [15] (RFL Bangladesh). The following supplies were provided for the intervention: Aquatabs ${ }^{\text {tw }}$ (Medentech, Wexford, Ireland) for water treatment, laundry detergent sachets for soapy water preparation and Lipid-based Nutrient Supplement (LNS; Nutriset, France). The intervention technologies and products were integrated with parallel behaviour-change promotion, described and displayed in greater detail in the companion paper on monitoring intervention coverage and quality [8]. Behavioural objectives were drinking treated, safely stored water, safe feces disposal, handwashing with soap at key times, and age-appropriate nutrition behaviours (promoted exclusive breastfeeding up to 6 months of age, for children aged 6-24 months complementary feeding and supplementation using LNS). There were six intervention arms comprising 4169 enrolled households in geographically matched clusters: (1) drinking water treatment and safe storage, (2) sanitation, (3) handwashing, (4) combined water + sanitation + handwashing, (5) nutrition, and (6) combined nutrition + water + sanitation + handwashing.

Each CHW was responsible for one cluster of one intervention arm. Each cluster consisted of six to eight geographically proximate households, identified as having a pregnant mother at enrollment, with an average diameter of $1 \mathrm{~km}$ (range $0.2-2.2 \mathrm{~km}$ ) and being separated from adjacent study clusters by at least $1 \mathrm{~km}$ (at least a 15 -min walk). The six intervention and two control clusters were grouped into trial blocks (Fig. 2).

\section{Lessons learned from prior WASH effectiveness, implementation, and formative research studies in Bangladesh}

We applied lessons learned from two prior effectiveness and implementation research studies in which several of 


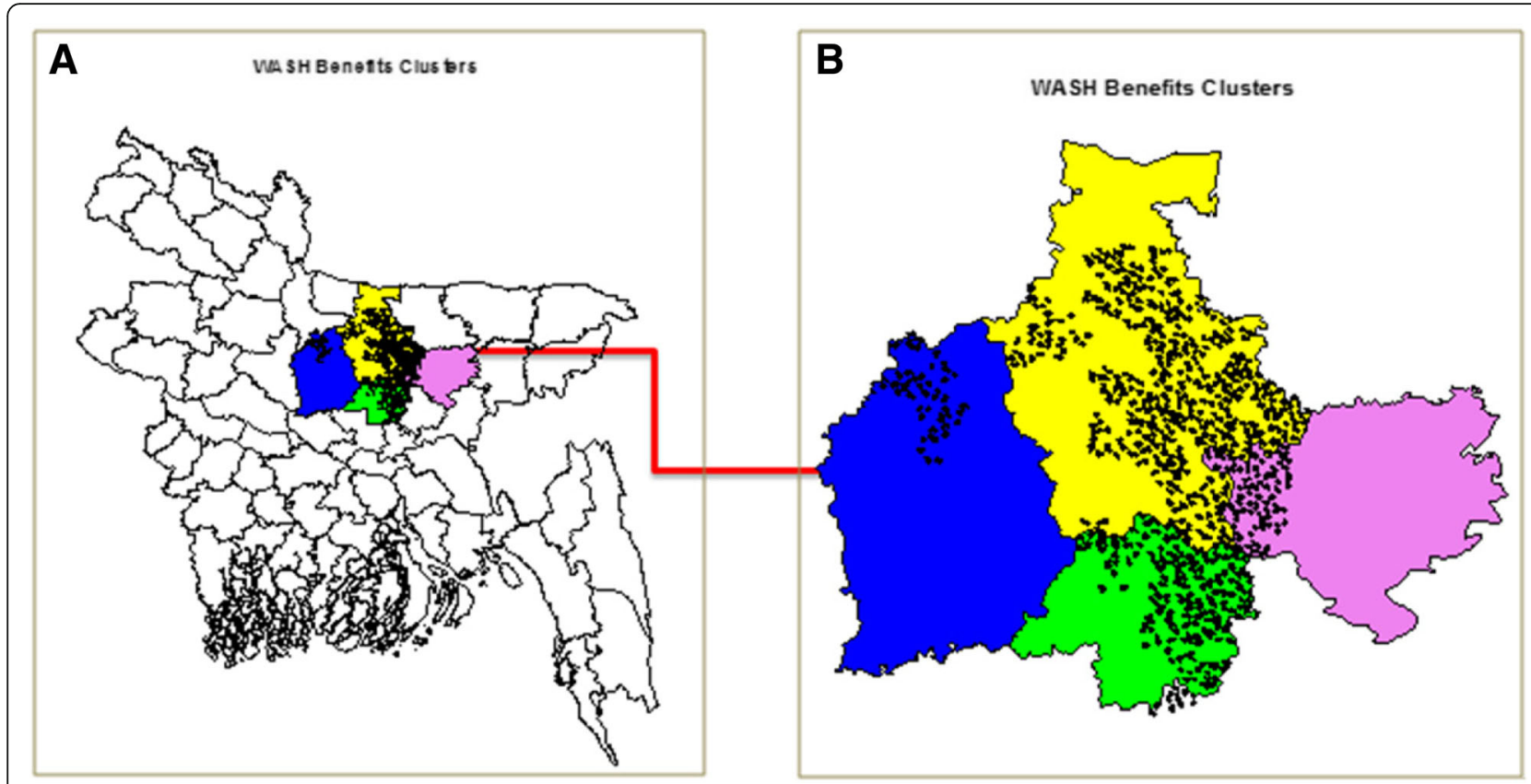

Fig. 1 Location of the WASH Benefits Bangladesh Study. a A map of Bangladesh showing districts in which the WASH Benefits study was conducted; Tangail (blue), Gazipur (green), Kishoreganj (pink) and Mymensingh (yellow). b WASH Benefits study clusters (indicated with black dots) within the four districts

the WASH Benefits Bangladesh study team members were involved (Table 3).

The effectiveness study 'Introduction of Cholera Vaccine in Bangladesh' (ICVB) [16] included a 2-year handwashing and chlorine water treatment intervention delivered to

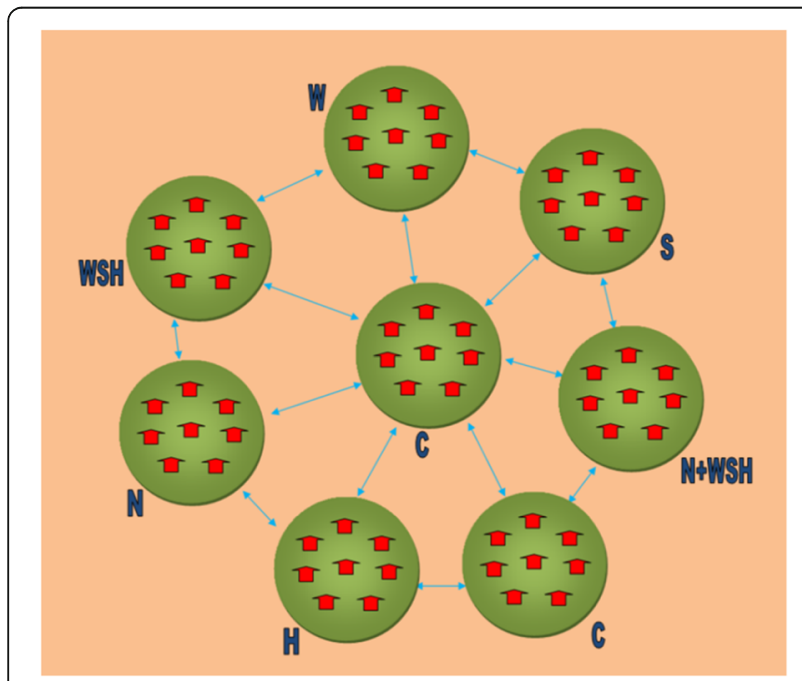

Fig. 2 WASH Benefits Bangladesh trial blocks. Each trial block comprised six intervention and two control clusters, each of 6 to 8 households with a pregnant woman (at enrollment) with $1 \mathrm{~km}$ buffer between consecutive clusters; $W$ water treatment and safe storage, $S$ sanitation, $H$ handwashing, N nutrition, $C$ control, WSH water treatment + sanitation + handwashing, $N+W S H$ nutrition + water treatment + sanitation + handwashing approximately 240,000 urban low-income household members. The study's 55 CHWs were recruited and supervised by a single non-governmental organization (NGO). The study team monitored $\mathrm{CHW}$ performance, technology, and behavioural uptake (defined in Table 2) and investigated implementation fidelity shortcomings which in turn triggered refresher training sessions for CHWs and/or CHW supervisors in addition to liaison with senior NGO management. However, the water treatment uptake was very low [17]. CHWs did not manage to reach all households as frequently as intended based on workload, faced early confusion about their roles, found enabling technology delivery difficult, and detected problems with quality and provision of technologies and supplies, identified by research field team reports, complicating delivery of the behaviour-change activities.

The Sanitation, Hygiene Education, and Water supply in Bangladesh program (SHEWA-B) included an implementation research component. It evaluated a WASH intervention delivered to 20 million people over 5 years (2007-2012). The program's 10,000 CHWs delivered behaviour-change promotion, coordinated through 40-60 NGOs that employed, trained, and independently monitored their performance. We detected that $\mathrm{CHW}$ visit frequency and health impact were low [2, 18, 19], and that CHWs felt over-burdened, were intermittently paid, and had few training sessions $[2,19]$.

We therefore aimed to put a system in place that ensured provision of enabling technologies and supplies that were feasible, acceptable, and of a high standard. Technology and 
Table 3 Examples of studies of water, sanitation and hygiene interventions conducted in Bangladesh corresponding to the three categories of research on behaviour-change interventions delivered by community health workers (CHWs)

\begin{tabular}{|c|c|c|c|c|}
\hline Type of research & $\begin{array}{l}\text { Example of this } \\
\text { type of research }\end{array}$ & $\begin{array}{l}\text { Scale, setting and duration of } \\
\text { study }\end{array}$ & $\begin{array}{l}\text { CHW to } \\
\text { household ratio }\end{array}$ & $\begin{array}{l}\text { System for } \mathrm{CHW} \text { oversight, training and } \\
\text { intervention dissemination }\end{array}$ \\
\hline Efficacy research & $\begin{array}{l}\text { WASH Benefits } \\
\text { Bangladesh study }\end{array}$ & $\begin{array}{l}\text { Population; } 4169 \\
\text { intervention } \\
\text { households; } \\
\text { Location: } 4 \text { rural } \\
\text { sub-districts } \\
\text { Duration; 2012-2015 } \\
\text { (2-year intervention exposure) }\end{array}$ & $\begin{array}{l}1: 8 \\
\text { CHWs; } N=540\end{array}$ & $\begin{array}{l}\text { CHW oversight; } \\
\text { Coordinated by study team (Fig. 3) } \\
\text { Transparent and rigorous recruitment } \\
\text { criteria and methods } \\
\text { Identified as employee to maintain morale } \\
\text { and prestige in the community } \\
\text { Delivery skills formally assessed } \\
\text { Accessible supervision, } 12 \text { CHWs/supervisor } \\
\text { CHWs received study technologies to } \\
\text { encourage CHW and recipient self-efficacy } \\
\text { Stipend paid using mobile phone network } \\
\text { Training: } \\
\text { Provided by project staff } \\
\text { Refreshers: scheduled and triggered by } \\
\text { fidelity measures } \\
\text { Included messages on study staff withdrawal } \\
\text { and intervention sustainability } \\
\text { Dissemination; } \\
\text { Based on communication plan and } \\
\text { IBM-WASH theoretical model }{ }^{2} \\
\text { Evaluated messages were understood by } \\
\text { recipients } \\
\text { Community meetings during roll out for } \\
\text { acceptability, expectation management, } \\
\text { conflict reduction } \\
\text { Sequenced technology and BCC component } \\
\text { delivery for combined interventions }\end{array}$ \\
\hline Effectiveness research & $\begin{array}{l}\text { Introduction of cholera } \\
\text { vaccine in Bangladesh }\end{array}$ & $\begin{array}{l}\text { Population; 240,000 } \\
\text { Location: urban slums, Dhaka } \\
\text { Duration: 2011-2013 (2-year } \\
\text { intervention exposure) }\end{array}$ & $\begin{array}{l}1: 290 \\
\text { CHWs; N = 55 }\end{array}$ & $\begin{array}{l}\text { CHW oversight } \\
\text { Single NGO with close project staff } \\
\text { involvement, } 16 \text { CHWs/supervisor } \\
\text { Training } \\
\text { Delivered by NGO, developed by project staff } \\
\text { Dissemination: NGO-hired CHWs from the } \\
\text { local community-delivered interpersonal } \\
\text { communications. NGO-delivered hardware }\end{array}$ \\
\hline Implementation research & $\begin{array}{l}\text { Sanitation, hygiene } \\
\text { Education and water } \\
\text { supply in Bangladesh } \\
\text { Health Impact Study }\end{array}$ & $\begin{array}{l}\text { Population } 20 \text { million } \\
\text { Location: } 58 \text { rural sub-districts } \\
\text { Duration: } 2007-2012 \text { (4-5-year } \\
\text { intervention exposure) }\end{array}$ & $\begin{array}{l}\text { Up to } 1: 550 \\
\text { CHWs; } N=10,000^{5}\end{array}$ & $\begin{array}{l}\text { CHW oversight; } \\
\text { multiple NGOs; individual NGOs responsible } \\
\text { for hiring and supervision } \\
\text { Training: multiple NGOs } \\
\text { Dissemination: multiple NGO-hired CHWs } \\
\text { from the local community, delivered } \\
\text { interpersonal communications }\end{array}$ \\
\hline
\end{tabular}

${ }^{1}$ Arnold et al. [6], www.washbenefits.net; ${ }^{2}$ Dreibelbis et al. [21]; ${ }^{3} \mathrm{CV} B$; the Introduction of Cholera Vaccine in Bangladesh trial [16]; ${ }^{4}$ SHEWA-B; Sanitation, Hygiene Education and Water supply in Bangladesh Health Impact Study [19]; ${ }^{5} \mathrm{~A}$ total of $\sim 10,000 \mathrm{CHWs}$ were engaged in dissemination, but not necessarily the full 5-year intervention period

NGO non-governmental organization

supply choices were based on formative research and pilot studies conducted from September 2010 to December 2012. Trials of improved practices compared enabling technology options and included baseline and 3-4-month follow-up surveys to measure uptake, and qualitative studies to assess technology and supply limitations, motivators, and barriers to refine the technologies and the behaviour-change strategy $[6,12,13,16,20]$ (WASH Benefits Bangladesh Pilot Assessments Report. 2012),). We encouraged behaviour change with a much lower ratio of CHWs-to-households and supportive reminder systems, through an intervention delivery system (Table 3) and described in detail below. We responded to detected implementation fidelity shortcomings [8].

\section{Intervention delivery system for the WASH Benefits efficacy study Trial oversight}

International oversight of the trial was achieved through a central coordinating group at University of California, Berkeley [6], which convened annual meetings from 2009 to 2015 that brought together the Technical Advisory Group (Fig. 3) and the senior scientific and management members of the trial.

Our organizational structure for intervention delivery (Fig. 3) built on lessons learned from the Introduction of Cholera Vaccine in Bangladesh (ICVB) and SHEWA-B intervention delivery structures. The Intervention Delivery 


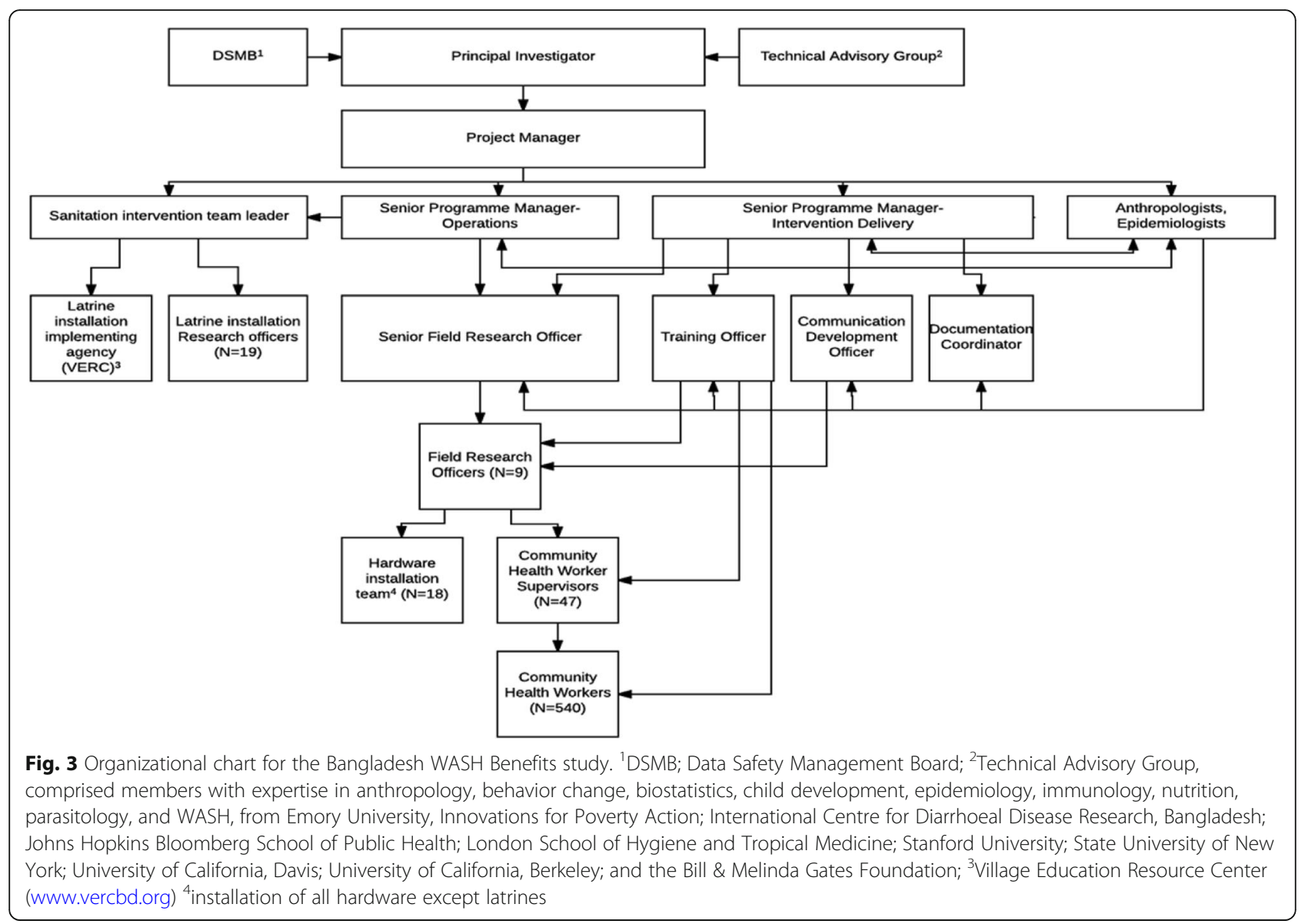

Team (comprising a senior program manager-intervention delivery, senior program manager-operations, Sanitation Intervention Team leader, senior field research officer, training officer, field research officers, $\mathrm{CHW}$ supervisors, and CHWs; Fig. 3) and the research team (comprising principal investigator, project manager, senior program managers, epidemiologists, anthropologists and collaborators forming the Technical Advisory Group), with the exception of collaborators, were co-located. We managed field intervention delivery through regular team phone calls, field meetings, field reports, and liaison with relevant government and other stakeholders. The Intervention Delivery Team rather than $\mathrm{NGO}(\mathrm{s})$ coordinated CHWs to ensure rapid identification of issues with intervention delivery.

\section{Community health worker oversight}

To recruit local CHWs, the Intervention Delivery Team used transparent selection methods and criteria that included consultation with community leaders, such as teachers and religious leaders, to identified candidate female residents from the study clusters. Candidates completed a written exam and interview. After candidates were offered employment, they were informed of their shared job responsibility, engagement, their pay rate and were provided training. Intervention Delivery Team members described potential benefits of becoming a CHW which included working with a reputable health organization, recognition by the community, gaining skills useful for future employment and they were told that they would receive an employment certificate at the end of their tenure.

$\mathrm{CHW}$ supervisors were first trained in direct intervention delivery based on the need to deliver an extensive and intensive intervention training plan. They subsequently trained the CHWs under their supervision ("train the trainer"). Thus, CHW supervisors developed a detailed knowledge of the intervention and its delivery, and a relationship with their team. The field implementation structure ensured that CHW supervisors were highly accessible, by cell phone and through regular visits, maintaining a low supervisor-to-CHW ratio (approximately 1 to 12; Fig. 3). CHW supervisors selected CHWs for regular visit rounds each month, especially for those they thought were under performing or where CHWs had identified uptake issues. Supervisors used a problem solving interactive approach rather than didactic instruction. Moreover, we encouraged informal communications with $\mathrm{CHW}$ supervisors by 
engaging CHWs in a number of social events arranged in the community and the field office to create an environment for interaction. CHWs were trained in technology and supply use, and were given technologies and supplies to use in their own homes, that their recipient household also received.

We developed a Training Plan and Manual for the CHW supervisors to ensure consistency across training sessions. $\mathrm{CHW}$ training was conducted using the guiding principles that training was an ongoing process that involved developing a relationship with supervisor-trainers, transferring knowledge through mutual trust and guidance, encouraging participation and developing confidence and ownership of the work. The first round of training included three components: basic training, intervention-specific training and classroom practice/role playing. Basic training included introduction of the project, description of CHW roles and responsibilities, introduction to behaviour-change principles based on the IBM-WASH theoretical framework [9] and interpersonal and counseling communication skills. Intervention-specific training was conducted for 4-9 days; longer duration was required for CHWs delivering combined interventions.

The research team that developed intervention content was also involved in training. Researchers were, therefore, available to respond to questions from $\mathrm{CHW}$ supervisor-trainers and CHWs about the rationale for intervention behaviours and technologies. The Intervention Delivery Team included a dedicated trainer (training officer) and a dedicated communication development officer who piloted and produced $\mathrm{CHW}$ job aids (Fig. 3). CHWs met with supervisors every month to exchange experiences and learned about the resulting additional or revised behaviour-change activities from the training officer. In addition to these monthly meetings, major refresher training was delivered to all CHW supervisors and CHWs from December 2013 to January 2014, approximately 12-15 months after intervention roll out. $\mathrm{CHW}$ work plans were developed with $\mathrm{CHW}$ supervisors, during training sessions.

CHWs were provided with institutional ID badges to enhance morale and prestige in the community and had their monthly stipends of approximately US $\$ 20$, equivalent to 5 days' full-time salary for a day laborer, delivered through the mobile phone network to ensure timely payments (Table 3).

\section{Intervention dissemination}

We allocated one CHW to each cluster, usually comprising between six and eight households spread across a $0.2-2.2-\mathrm{km}$ area. Clusters had approximately $1 \mathrm{~km}$ between each other to limit intervention spillover.

Dissemination (communicating tailored information to target audiences) was guided by the study behaviour-change strategy, which was based on the IBM-WASH theoretical framework [21] and the prior formative research [6, 12, 13, 16, 20] (WASH Benefits Bangladesh Pilot Assessments Report. 2012)). The study behaviour-change strategy included triggers for refresher training and was used as a method to document intervention revisions. The strategy was modified to include additional promoted behaviours to enhance technology and behavioural uptake (Table 2), recognized during field meetings (manuscript in preparation).

The Intervention Delivery Team conducted community meetings in each intervention cluster, to introduce CHWs, technologies, supplies, and behaviours, and additionally to manage expectations and minimize conflicts identified during the piloting period.

Free provision of technologies and supplies followed a roll-out plan that incorporated actions for hardware repair and replacement, and supply replenishment. For households that received combined interventions, dissemination was sequenced for each intervention component to ensure timely technology and supply delivery and optimal behavioural and technology uptake. During training CHWs were instructed to conduct at least weekly home visits during the first 6 months of the intervention, and at least once monthly visits in the second year.

The dissemination phase began from September 2012 to first 10 trial blocks (Fig. 2), monitored and refined during a 2-3 month period, then rolled out to the remaining trial blocks in nine phases, to accommodate the logistics and the large number of staff members needed to deploy quality interventions (Table 3 ).

\section{Intervention delivery monitoring}

We employed several methods to monitor intervention delivery progress. Monthly fidelity measurements were made from 3 months after the intervention was delivered and compared to a priori benchmarks. Fidelity indicators were mostly observable proxies for target behaviours, and some household reports, described in detail in the companion paper on monitoring intervention coverage and quality in this three-paper series [8]. In brief, fidelity indicators included the presence of chlorine in stored water, spot checks for the following: sani-scoop accessibility, intact functional household latrine water seal, the presence of water and soap at handwashing locations (near the toilet and the cooking area) and inspection for sachets of LNS consumed. We also obtained data on the following reported indicators: hearing messages on nutrition and/ or LNS, location and method of disposal for child's last bowel motion. Households were asked to produce the following within $10 \mathrm{~s}$ : child potties, sani-scoops, LNS sachets. Structured observations were performed from February to July 2014 (approximately 18 months after dissemination commenced). Observations were conducted among one household randomly selected 
each from intervention arm $(N=6)$ and from the double sized control $(N=2)$ from each trial block from nine successive implementation phases totalling 324 households. Details on household selection, observation methods, analyses, and direct assessment of behavioural uptake are provided in the companion paper [9].

The senior program manager-intervention delivery, senior program manager-operations and members of the research team that had developed the interventions made periodic field visits, and reviewed monthly reports from intervention delivery staff and CHWs, and from international behaviour-change collaborator visits. Two-weekly calls made from July 2011 to April 2014 among the principal investigator, Bangladesh-based project management staff, and the research team included discussions on intervention delivery troubleshooting and revisions to technology and behaviour-change components; subsequently these were held each month, as issues for discussion lessened.

To measure CHW intervention delivery quality, the Intervention Delivery Team conducted internal $\mathrm{CHW}$ performance monitoring and reviewed monthly program reports and staff meeting reports. A donor required process evaluation by an external monitoring agency and this was conducted by the Centre for Research and Management Consulting (SRGB) [10-12].

\section{Ethics approval and consent to participate}

All households provided written informed consent at enrollment. The protocol was reviewed and approved by human subjects review committees at the International Centre for Diarrhoeal Disease Research, Bangladesh (icddr,b) and at the University of California, Berkeley. The WASH Benefits trial was registered at ClinicalTrials.gov (NCT01590095).

\section{Results}

Implementation monitoring highlighted both successes and shortcomings. Fidelity benchmarks were attained by the fourth intervention assessment month demonstrating moderate to high technology and behavioural uptake, described in the companion paper on monitoring WASH Benefits intervention coverage and quality [8]. This was sustained throughout the program period, described in the companion paper on WASH Benefits intervention uptake [9] for single and combined intervention recipient households. Similar technology and behavioural uptake indicators were detected by the external monitoring agency [22-24]. Periodic internal CHW monitoring resulted in discontinuation of a small number of low performers $(n=33)$. During the intervention period, a total $156 \mathrm{CHWs}$ discontinued service, the most common reason being migration of some type (moved with family, moved abroad, moved after marriage; $n=50$ ).

We attempted to address problems as they were detected by the Intervention Delivery Team. The first and most important difficulty was developing a way to manage an intensive training timetable. Considering the complexity of the intervention design and distribution of $\mathrm{CHW}$ by intervention type and arm, we initially engaged a professional trainer group to lead the CHW training. They developed the training guideline and communication package and we assigned them to conduct the first batch of training. Despite their expertise in training activities, we observed that the trainer group was not effectively engaging trainees. We found that their highly structured conventional methods likely did not fit with the varied trainee background, particularly for an inexperienced group of selected CHWs. We also understood that $\mathrm{CHW}$ motivation would be key and the professional trainers seemed lacking. Thus, we developed an internal training resource group from among our team, thoroughly analyzed the gaps and revised the training methods and materials. Moreover, supervisors were found to be initially minimally engaged with the training and their minimal involvement in training was a lost opportunity for becoming acquainted with intervention detail and developing rapport with the CHWs. Additionally, based on the intervention roll-out timeline, we anticipated that CHW training would take approximately $12-13$ months so we used the train the trainer method (described earlier). During plans for training we detected that it was important to further define supervisory roles, hence the development of the Training Manual (described earlier).

Another difficulty was the need to deliver six different interventions, and the potential distance between randomly assigned study clusters. If a CHW had to deliver an intervention in more than one cluster, it would have to be a geographically proximate one; there would have been the potential for $\mathrm{CHW}$ s to become confused about message delivery.

Early in the roll-out period, the Intervention Delivery Team detected issues with the pace of hardware installation which could impact the intervention timeline. Latrines were installed for 4533 households and involved numerous construction and quality assurance steps and were thereby delivered independently from the other sanitation technologies and behavioural promotion. Thus, latrine roll out began earlier than other sanitation and other interventions due to an anticipated longer installation period.

To maximize uptake throughout the intervention period, new behaviour-change activities were developed, to address sub-optimal practices detected from structured observations, and to address intervention fatigue reported by CHWs during monthly meetings. Initiatives included further technology use and behaviours that related to the index child age, increasing self-efficacy, increasing roles for men, and decreased emphasis on behaviors that were commonly being practiced. During a 
6-month period of political instability, mid-intervention (January to June 2014), we ensured field staff safety through close oversight by the Intervention Delivery Team members at field offices with staff accommodation facilities.

\section{Discussion}

WASH Benefits Bangladesh study intervention delivery built on lessons from prior implementation research [18] and effectiveness research studies $[16,18]$, to guide development of the intervention delivery system for this efficacy study. As reported in the companion papers in this issue of the journal, the implementation fidelity and uptake data demonstrated that WASH behaviour change met targets considered sufficient for a large-scale efficacy trial $[8,9]$. Thus, when interventions were assessed for impact on linear growth and childhood diarrhoea, the WASH Benefits study demonstrated that children from households that received nutrition alone or combined with WASH interventions had significantly greater linear growth. Additionally, children from households that received any of the interventions, with the exception of water treatment, had significantly lower prevalence of diarrhoea. Intervention effects in an efficacy trial cannot be determined when intervention uptake is low.

The high intervention uptake achieved in the WASH Benefits Bangladesh study may be attributed to several factors. Prior formative research and pilot trials provided researchers with some clear choices on attractive, durable enabling technologies and supplies that were provided to enrolled households and would likely encourage behavioural uptake; choices and behaviour-change promotion were underpinned by a theory- and evidence-based behaviour-change strategy. We had conducted community pilots for the ICVB effectiveness study, but behavioural uptake was considerably lower [16]. However, the ICVB pilot period was shortened by an intervention delivery deadline, in line with vaccine delivery, which meant that we were less able to troubleshoot community and household-level problems, particularly with the liquid chlorine-based water treatment intervention. Moreover, in the ICVB intervention, several adjoining unrelated households were expected to share study-provided technologies and supplies [17]. Lower uptake was possibly attributed to additional constraints in urban, low-income environments [13].

$\mathrm{CHW}$-accessible supervision has been highlighted as critical for successful CHW-delivered interventions [25-27]. Particular attention was given to $\mathrm{CHW}$ supervision, management, and performance monitoring, based on limitations detected during the SHEWA-B implementation research study, which detected low uptake [2, 19]. SHEWA-B involved more than 10,000 CHWs, each expected to cover 450-550 households [2], who were hired and supervised by $40-60$ NGOs during the 5-year intervention period. In an effectiveness research study conducted in India, six different NGOs were contracted to deliver the intervention, and similarly sub-optimal behavioural uptake was found [28]. In the ICVB effectiveness study, a single NGO hired and supervised CHWs, with monthly input from the study research team; however, CHW supervision problems were not totally avoided. In the WASH Benefits Bangladesh efficacy study, the Intervention Delivery Team directly supervised CHWs ensuring frequent interaction, and greater control over intervention delivery.

Training can impact CHW performance [25-27, 29, 30]. The advantages of the training program in this study were that it was developed in collaboration with the research team which had conducted the formative research and pilot studies, and it comprised a train the trainer method for $\mathrm{CHW}$ supervisors, longer duration $\mathrm{CHW}$ trainings, monthly sessions with the training officer, and refresher sessions driven by adjustments in the behaviour-change strategy. Monthly interactive training meetings that encouraged and acknowledged problem identification likely assisted job satisfaction. In contrast, the SHEWA-B program CHWs received 15 days of initial training in 2007 and 12 total days of refresher training delivered by third-party NGOs between 2009 and 2015 [19].

The supervisor-to-CHW and CHW-to-household ratios in this efficacy study were considerably lower than typical programs and thus facilitated open communication channels. CHW workload has been examined with respect to program delivery quality, and studies have demonstrated that including additional tasks may not compromise quality [31], but heavy workload can impact motivation, performance, and job satisfaction [27]. These indicators were all high among our CHWs, when assessed in a qualitative study (manuscript in preparation).

Non-monetary rewards can contribute to morale and performance [25-27]. For the majority of our CHWs this position was the first paid employment; we used initiatives that we thought would enhance prestige in the community and general job satisfaction while minimizing $\mathrm{CHW}$ turnover. We provided ID badges on lanyards, signifying that they were working women and associated with a known and respected health organization. We ensured timely stipend payments through mobile phone networks; frustration over delayed payments was reported by $\mathrm{CHWs}$ during the SHEWA-B impact assessment [19].

The intervention delivery system brought together a theory- and evidence-based behaviour-change strategy (Leontsini et al., manuscript in preparation), regular staff interaction at each level of the Intervention Delivery Team, continuous quality improvement principles, and learning from other WASH trials in Bangladesh (Table 3). The co-location of intervention delivery and research staff is relatively uncommon, and likely allowed each group to share and understand the intervention 
delivery constraints and strengths, ensuring continuous communication and a rapid response to problems identified in the field. An alternative strategy could include assembling research and delivery teams with key program stakeholders in the field to develop and revise a Program Impact Pathway, as described for nutrition interventions [32-34].

An important limitation of our intervention delivery was cost; this was an efficacy trial. Provision of enabling technologies and supplies free of cost to households is not feasible for larger-scale implementation. Opportunities for savings include revising technologies to include simpler hardware, providing technology and product subsidies, or encouraging households to provide some of their own components [35], which may increase feasibility. Intensive behaviour-change activities using frequent one-on-one visits were also expensive and not feasible for larger efficacy trials or implementation programs. However, some aspects of the intervention delivery system, such as communication approaches that focus on developing problem-solving skills rather than didactic transfer of information and lower supervisor-to-CHW ratios could be adopted at a moderate cost.

\section{Conclusions}

Achieving sufficient WASH intervention uptake is attainable; efforts to reduce intervention costs need further exploration. Prior studies have demonstrated that lower intensity is cheaper [36]. However, studies that compare the impact of behavioural and technology uptake at different CHW-visit intensity levels have not been conducted. Regular training that includes office-based interactive sessions with CHWs and their supervisors is costly. Potentially cheaper electronic training (e-training) methods have been employed in high-income countries [37, 38] and will likely appeal to increasingly technology-savvy members of low-income countries where mobile phone and smartphone penetration is high and increasing.

Access to, and interaction with, supervisors has been described previously as impacting on performance $[25,26]$. The supervisor-to-CHW and CHW-to-household ratios in WASH Benefits Bangladesh that facilitated open communication channels were considerably lower than typical programs. Exploring effectiveness of higher ratios on $\mathrm{CHW}$ performance is needed.

Sustainability of a program beyond program staff presence is an important intervention objective [39], typically addressed in implementation research studies. The extent to which CHW performance impacts uptake beyond the promotion period is an important area for future research.

\section{Abbreviations}

BCC: Behaviour-change communication; CHW : Community health worker; IBM-WASH: Integrated Behavioral Model for Water, Sanitation, and Hygiene; icddr,b: International Centre for Diarrhoeal Disease Research, Bangladesh;
ICVB: Introduction of Cholera Vaccine in Bangladesh study; NGO: Nongovernmental organization; SHEWA-B: Sanitation, Hygiene Education, and Water supply in Bangladesh program; SRGB: Centre for Research and Management Consulting; WASH: Water, sanitation, and hygiene

\section{Acknowledgements}

The authors acknowledge the WASH Benefits Bangladesh study collaborators and acknowledge the cooperation of the study households and communities that were visited several times for intervention delivery and data collection.

\section{Funding}

This research study was funded by the Bill \&Melinda Gates Foundation grant (OPPGD759) through the University of California Berkeley. icddr,b acknowledges with gratitude the commitment of the Bill \&Melinda Gates Foundation to its research efforts. Icddr,b is also grateful to the Governments of Bangladesh, Canada, Sweden, and the UK for providing core/unrestricted support.

\section{Availability of data and materials}

Data can be made available through the authors.

\section{Authors' contributions}

LU drafted the manuscript with the listed co-authors and provided input on the intervention technology and behaviour components, the delivery methods and data collection. FB led the intervention implementation and provided input on the intervention technology and behaviour components, the delivery methods and data collection.. EL with FB developed the intervention communication strategy. MR provided oversight on the intervention implementation and provided input on the intervention technology and behaviour components, the delivery methods, and data collection, SPL conceived of the study and participated in its design, coordination, and analysis and provided input on the intervention technology and behaviour components, the delivery methods and data collection.. SA, AMN, FAN, KJ, FH, and SMP developed the intervention technology and behaviour components, the delivery methods, and data collection. MM developed and led the training components of the trial. PW quided the behaviour- change component, and the manuscript structure. All authors read and approved the final manuscript.

Ethics approval and consent to participate

All households provided written informed consent at enrollment. The protocol was reviewed and approved by human subjects review committees at the International Centre for Diarrhoeal Disease Research, Bangladesh (icddr,b) and at the University of California, Berkeley. The WASH Benefits trial was registered at ClinicalTrials.gov (NCT01590095).

\section{Consent for publication}

All co-authors have reviewed this version of the manuscript and provided consent for manuscript submission.

\section{Competing interests}

The authors declare that they have no competing interests.

\section{Publisher's Note}

Springer Nature remains neutral with regard to jurisdictional claims in published maps and institutional affiliations.

\section{Author details}

${ }^{1}$ Infectious Disease Division, Environmental Intervention Unit, Enteric and Respiratory Disease Program, International Centre for Diarrhoeal Disease Research, Bangladesh (icddr,b), 68 Shahed Tajuddin Ahmed Sarani, Mohakhali, Dhaka 1212, Bangladesh. ${ }^{2}$ Johns Hopkins Bloomberg School of Public Health, Baltimore, MD, USA. ${ }^{3}$ Rollins School of Public Health, Emory University, Atlanta, GA, USA. ${ }^{4}$ Stanford University, Stanford, CA, USA.

Received: 27 April 2017 Accepted: 25 May 2018

Published online: 06 July 2018

\section{References}

1. Ejemot RI, Ehiri JE, Meremikwu MM, Critchley JA. Hand washing for preventing diarrhoea. Cochrane Database Syst Rev. 2008;1:CD004265.

2. icddr b. UNICEF, icddr,b, SHEWA-B Program Health Impact Study Report. 2014. https://www.unicef.org/bangladesh/SHEWA-B_HIS.pdf. 
3. Pickering AJ, Djebbari H, Lopez C, Coulibaly M, Alzua ML. Effect of a community-led sanitation intervention on child diarrhoea and child growth in rural Mali: a cluster-randomised controlled trial. Lancet Glob Health. 2015; 3(11):e701-11.

4. Patil SR, Arnold BF, Salvatore AL, Briceno B, Ganguly S, Colford JM Jr, Gertler PJ. The effect of India's total sanitation campaign on defecation behaviors and child health in rural Madhya Pradesh: a cluster randomized controlled trial. PLoS Med. 2014;11(8):e1001709.

5. Cha S, Kang D, Tuffuor B, Lee G, Cho J, Chung J, Kim M, Lee H, Lee J, Oh C. The effect of improved water supply on diarrhea prevalence of children under five in the Volta region of Ghana: a cluster-randomized controlled trial. Int J Environ Res Public Health. 2015;12(10):12127-43.

6. Arnold BF, Null C, Luby SP, Unicomb L, Stewart CP, Dewey KG, Ahmed T, Ashraf S, Christensen G, Clasen T, et al. Cluster-randomised controlled trials of individual and combined water, sanitation, hygiene and nutritional interventions in rural Bangladesh and Kenya: the WASH benefits study design and rationale. BMJ Open. 2013;3(8):e003476.

7. Luby SP, Rahman M, Arnold BF, Unicomb L, Ashraf S, Winch PJ, Stewart CP, Begum F, Hussain F, Benjamin-Chung J, et al. Effects of water quality, sanitation, handwashing, and nutritional interventions on diarrhoea and child growth in rural Bangladesh: a cluster randomised controlled trial. Lancet Glob Health. 2018;6(3):e302-15.

8. Rahman M, Ashraf S, Unicomb L, Mainuddin AKM, Parvez SM, Begum F, Das KK, Naser AM, Hussain F, Clasen T, et al. WASH Benefits Bangladesh trial: system for monitoring coverage and quality in an efficacy trial.

9. Parvez SM, Azad R, Rahman M, Unicomb L, Ram PK, Naser AM, Stewart CP, Jannat K, Rahman MJ, Leontsini E, et al. Achieving optimal technology and behavioral uptake of single and combined interventions of water, sanitation hygiene and nutrition, in an efficacy trial (WASH Benefits) in rural Bangladesh.

10. Curran GM, Bauer M, Mittman B, Pyne JM, Stetler C. Effectivenessimplementation hybrid designs: combining elements of clinical effectiveness and implementation research to enhance public health impact. Med Care. 2012;50(3):217-26.

11. Ercumen A, Naser AM, Unicomb L, Arnold BF, Colford JM Jr, Luby SP. Effects of source- versus household contamination of tubewell water on child diarrhea in rural Bangladesh: a randomized controlled trial. PLoS One. 2015; 10(3):e0121907.

12. Sultana R, Mondal UK, Rimi NA, Unicomb L, Winch PJ, Nahar N, Luby SP. An improved tool for household faeces management in rural Bangladeshi communities. Tropical Med Int Health. 2013;18(7):854-60.

13. Hussain F, Luby SP, Unicomb L, Leontsini E, Naushin T, Buckland AJ, Winch PJ. Assessment of the acceptability and feasibility of child Potties for safe child feces disposal in rural Bangladesh. Am J Trop Med Hyg. 2017;97(2):469-76.

14. Hussain F, Clasen T, Akter S, Bawel V, Luby SP, Leontsini E, Unicomb L, Barua MK, Thomas B, Winch PJ. Advantages and limitations for users of double pit pour-flush latrines: a qualitative study in rural Bangladesh. BMC Public Health. 2017;17(1):515.

15. Hulland KR, Leontsini E, Dreibelbis R, Unicomb L, Afroz A, Dutta NC, Nizame FA, Luby SP, Ram PK, Winch PJ. Designing a handwashing station for infrastructure-restricted communities in Bangladesh using the integrated behavioural model for water, sanitation and hygiene interventions (IBMWASH). BMC Public Health. 2013;13:877

16. Qadri F, Ali M, Chowdhury F, Khan Al, Saha A, Khan IA, Begum YA, Bhuiyan TR, Chowdhury MI, Uddin MJ, et al. Feasibility and effectiveness of oral cholera vaccine in an urban endemic setting in Bangladesh: a cluster randomised open-label trial. Lancet. 2015:386(10001):1362-71.

17. Najnin N, Leder K, Qadri F, Forbes A, Unicomb L, Winch PJ, Ram PK, Leontsini E, Nizame FA, Arman S, et al. Impact of adding hand-washing and water disinfection promotion to oral cholera vaccination on diarrhoeaassociated hospitalization in Dhaka, Bangladesh: evidence from a cluster randomized control trial. Int J Epidemiol. 2017;46(6):2056-66.

18. Huda TM, Unicomb L, Johnston RB, Halder AK, Yushuf Sharker MA, Luby SP. Interim evaluation of a large scale sanitation, hygiene and water improvement programme on childhood diarrhea and respiratory disease in rural Bangladesh. Soc Sci Med. 2012;75(4):604-11.

19. Benjamin-Chung J, Sultana S, Halder AK, Ahsan MA, Arnold BF, Hubbard AE, Unicomb L, Luby SP, Colford JM Jr. Scaling up a water, sanitation, and hygiene program in rural Bangladesh: the role of program implementation. Am J Public Health. 2017;107(5):694-701.

20. Ashraf S, Nizame FA, Islam M, Dutta NC, Yeasmin D, Akhter S, Abedin J, Winch PJ, Ram PK, Unicomb L, et al. Nonrandomized trial of feasibility and acceptability of strategies for promotion of soapy water as a handwashing agent in rural Bangladesh. Am J Trop Med Hyg. 2017:96(2):421-9.

21. Dreibelbis R, Winch PJ, Leontsini E, Hulland KR, Ram PK, Unicomb L, Luby SP. The integrated Behavioural model for water, sanitation, and hygiene: a systematic review of behavioural models and a framework for designing and evaluating behaviour change interventions in infrastructure-restricted settings. BMC Public Health. 2013;13(1):1015

22. SRGB. Process Evaluation for WASH Benefits Study in Bangladesh. In: Centre for Research \& Management Consulting; 2013.

23. SRGB. Process Evaluation for WASH Benefits Study in Bangladesh, Second phase. In: Centre for Research \& Management Consulting; 2014

24. SRGB. Process Evaluation for WASH Benefits Study in Bangladesh, Third phase. In: Centre for Research \& Management Consulting; 2015.

25. Rowe AK, de Savigny D, Lanata CF, Victora CG. How can we achieve and maintain high-quality performance of health workers in low-resource settings? Lancet. 2005;366(9490):1026-35.

26. Pallas SW, Minhas D, Perez-Escamilla R, Taylor L, Curry L, Bradley EH. Community health workers in low- and middle-income countries: what do we know about scaling up and sustainability? Am J Public Health. 2013;103(7):e7482.

27. Kok MC, Dieleman M, Taegtmeyer M, Broerse JE, Kane SS, Ormel H, Tijm MM, de Koning KA. Which intervention design factors influence performance of community health workers in low- and middle-income countries? A systematic review. Health Policy Plan. 2015;30(9):1207-27.

28. Clasen T, Boisson S, Routray P, Torondel B, Bell M, Cumming O, Ensink J, Freeman $M$, Jenkins $M$, Odagiri $M$, et al. Effectiveness of a rural sanitation programme on diarrhoea, soil-transmitted helminth infection, and child malnutrition in Odisha, India: a cluster-randomised trial. Lancet Glob Health. 2014;2(11):e645-53.

29. Briscoe C, Aboud F. Behaviour change communication targeting four health behaviours in developing countries: a review of change techniques. Soc Sci Med. 2012;75(4):612-21.

30. Nguyen DT, Leung KK, McIntyre L, Ghali WA, Sauve R. Does integrated management of childhood illness (IMCI) training improve the skills of health workers? A systematic review and meta-analysis. PLoS One. 2013;8(6): e66030

31. Puett C, Coates J, Alderman H, Sadruddin S, Sadler K. Does greater workload lead to reduced quality of preventive and curative care among community health workers in Bangladesh? Food Nutr Bull. 2012;33(4):273-87.

32. Avula R, Menon P, Saha KK, Bhuiyan MI, Chowdhury AS, Siraj S, Haque R, Jalal CS, Afsana K, Frongillo EA. A program impact pathway analysis identifies critical steps in the implementation and utilization of a behavior change communication intervention promoting infant and child feeding practices in Bangladesh. J Nutr. 2013;143(12):2029-37.

33. Menon P, Covic NM, Harrigan PB, Horton SE, Kazi NM, Lamstein S, Neufeld L, Oakley E, Pelletier D. Strengthening implementation and utilization of nutrition interventions through research: a framework and research agenda. Ann N Y Acad Sci. 2014:1332:39-59.

34. Rawat R, Nguyen PH, Ali D, Saha K, Alayon S, Kim SS, Ruel M, Menon P. Learning how programs achieve their impact: embedding theory-driven process evaluation and other program learning mechanisms in alive \& thrive. Food Nutr Bull. 2013;34(3 Suppl):S212-25.

35. Biswas D, Nizame FA, Sanghvi T, Roy S, Luby SP, Unicomb LE. Provision versus promotion to develop a handwashing station: the effect on desired handwashing behavior. BMC Public Health. 2017;17(1):390.

36. Rajaraman D, Varadharajan KS, Greenland K, Curtis V, Kumar R, Schmidt WP, Aunger R, Biran A. Implementing effective hygiene promotion: lessons from the process evaluation of an intervention to promote handwashing with soap in rural India. BMC Public Health. 2014:14:1179.

37. Nilsson A, Engstrom M. E-assessment and an e-training program among elderly care staff lacking formal competence: results of a mixed-methods intervention study. BMC Health Serv Res. 2015;15:189.

38. Dennis E, Banks P, Murata LB, Sanchez SA, Pennington C, Hockersmith L, Miller R, Lambe J, Feng J, Kapadia M, et al. Validation of an Electronic Program for Pathologist Training in the Interpretation of a Complex Companion Diagnostic Immunohistochemical Assay. Hum Pathol. 2016;56: 194-203.

39. Bennett S, Singh S, Ozawa S, Tran N, Kang JS. Sustainability of donor programs: evaluating and informing the transition of a large HIV prevention program in India to local ownership. Glob Health Action. 2011;4. https://doi. org/10.3402/gha.v4i0.7360 